\title{
2002: LOS ISRAELITAS DE AHORA
}

\section{Enrique Espinoza-Benavides Joyo}

EN EL PRESENTE TRABAJO trataré sobre el grupo religioso "Asociación Evangélica de la Misión Israelita del Nuevo Pacto Universal" (AEMINPU) en dos momentos:

a) Durante la creación expansión y muerte del líder religioso

b) Situación del grupo religioso después de la muerte física del líder.

Este movimiento religioso israelita hace su aparición en el año 1956, y su fundador es Ezequiel Ataucusi Gamonal, zapatero de oficio, profeta que inscribe su movimiento religioso en registros públicos el año 1969.

Una de las características de este movimiento religioso es la procedencia de sus feligreses, personas inicialmente originarias del sur del Perú (Huancavelica y Ayacucho, entre otros), quechuahablantes, con un nivel educativo elemental. Su ámbito laboral era la agricultura en la selva central del Perú (valle de Chanchamayo).

La doctrina de Ezequiel proviene del adventismo, del cual se desgaja y añade prácticas del Antiguo Testamento, como son el holocausto, las fiestas de las cabañas, el bautizo, la expiación... Ezequiel 


\section{ENRIQUE ESPINOZA - BENAVIDES JOYO}

hace patentes sus creencias milenaristas (fin eminente del mundo) y predica la "ley real" (decálogo de Moisés).

Esta religión se caracteriza por ser básicamente seguidores del Antiguo Testamento, y Ezequiel, que es el "Jesucristo" encarnado, logrará salvar a sus seguidores del fin del mundo inminente. Es un líder mesiánico, a través de él se consigue la salvación, sus palabras y consejos son la buena nueva y seguirlo será motivo de salvar no solamente el alma sino también la vida.

Por esta época se presentan las fechas del fin del mundo, que se van cambiando gracias a Ezequiel, pues con sus ruegos a Dios éste se va retrasando.

\section{EL PERÚ COMO PAÍS PRIVILEGIADO}

Dios le reveló a Ezequiel que desde el Perú derramaría su Espíritu Santo a todo el mundo. Para que las naciones se conviertan, los israelitas propalan su doctrina mediante campañas, panfletos y revistas.

Todas las afirmaciones de los israelitas, ya sean políticas 0 religiosas, son sustentadas por citas bíblicas. Por ejemplo, la afirmación "el Perú es un país privilegiado" está sustentada en una cita que se refiere a 'a "ciudad del sol". Los israelitas se preguntan: ¿cuál es la ciudad del sol?, y se responden: Cusco, de allí Dios derramará su gracia, por lo tanto el Perú es un país privilegiado.

\section{LA PALABRA DE EZEQUIEL}

Ezequiel logra por su catequesis y sus interpretaciones de la Biblia autodenominarse "el hermano mayor" o "el hijo unigénito": Sus seguidores lo llaman "el Padre", "el Príncipe", "el Cordero", "el Maesiro". Sus charlas religiosas tocaban temas sociales y personales y estaban dirigidas sobre todo a campesinos en la ciudad, vendedores, ambulantes, empleadas domésticas, etc., quienes necesitaban una palabra de aliento en su difícil inserción en el trabajo. En el caso de Lima, la migración los convierte en personas marginales socialmente, debido a su escaso nivel educativo. 
2002: LOS ISRAELITAS DE AHORA

\section{LOS ISRAELITAS EN LIMA}

En la década del 60, los israelitas comienzan a tener presencia social en los diferentes barrios marginales (pueblos jóvenes) de Lima. Sus seguidores fundaron iglesias en el Augustino, Comas y en casi todas las zonas urbanas periféricas de la ciudad de Lima.

En Lima se gesta la articulación administrativa, sencilla en un inicio, pero en un segundo momento empieza a complejizarse y se divide la administración religiosa en los conos de la ciudad y se empadronan las diferentes iglesias que libremente se fundaban, en las cuales no tenía injerencia directa la oficina central.

Paralelamente, en los años 60, los israelitas inician programas de colonización en las fronteras del Perú con otros países, lo que ellos denominarán "fronteras vivas", concertadas con el Gobierno central. Un ejemplo de esto es el proyecto Pichis-Palcazu, además de otras iniciativas propias de los israelitas.

\section{El LLAMADO POLÍTICO}

A finales de la década de los 80 , los israelitas ingresan a la política y postulan a las elecciones municipales, logrando ocupar algunos cargos a regidores. En el año 1990, Ezequiel participa como candidato presidencial con el grupo político de su agrupación religiosa, Frente Popular Agrícola del Perú (FREPAP). Aquí conoce la derrota y la explicación que da a sus seguidores del porqué de su pérdida, siendo hijo de Dios, era que Dios lo quería humillar para después ensalzarlo. Durante esta campaña se adopta la tecnología del desarrollo agrario seguido por los incas, y en el campo ético se apelaba también a las leyes del incario: "no robar, no mentir, no ser ocioso".

Las siguientes campañas políticas tienen una estrategia más cuidadosa. Cada iglesia se convirtió en local partidario, se dotó de carné político a sus seguidores, se capacitó cómo votar y se fundaron comités de prensa y propaganda que repartían a lo largo de todo el país comunicados y directivas detallados de concentraciones, mítines y volantes. El asistencialismo se hizo presente cuando los israelitas comenzaron a promover ferias populares, donde se expendían productos agrícolas de su propia producción a bajo costo. 


\section{LA CAMPAÑA MODELO}

En el año 1995, en las elecciones generales, Ezequiel y sus seguidores desplegaron todo su poder de convocatoria política, personal y mediática a lo largo de todo el Perú. Los medios de comunicación fueron usados en toda su gama y posibilidades. En radio se emitía un espacio de una hora diaria, donde se leían estudios religiosos y se hacía proselitismo político; también se convocó a la prensa escrita y tenían una regular presencia en los espacios políticos de prensa televisiva.

La propaganda política impresa era dirigida desde su sede central, que remitía los volantes, afiches, comunicados y directivos de manera homogénea a todo el país.

En estas elecciones, un israelita ocupó una curul parlamentaria, a diferencia de las anteriores y posteriores campañas de elecciones generales, en las que sólo lograron curules parlamentarias algunas personas invitadas a participar en su lista parlamentaria.

\section{ISRAELITAS A PARTIR DEL 2000}

Durante las elecciones generales del año 2000, Ezequiel no se hizo presente como en campañas anteriores, debido a los achaques propios de su enfermedad.

A nivel formal estuvo inscrito como candidato presidencial; sin embargo, no participó activamente de acuerdo a la coyuntura política del momento (firma de acuerdo entre políticos). El resultado fue desalentador, porque, si bien FREPAP consiguió dos curules parlamentarias (de invitados a su lista parlamentaria), éstos se pasaron a las filas del oficialismo del momento. A raíz de este incidente, el FREPAP otorga su apoyo al candidato opositor al oficialismo en la segunda vuelta.

\section{MUERTE DEL LÍDER}

En el año 2000 fallece Ezequiel y provoca en toda la feligresía una gran conmoción. 


\section{2: LOS ISRAELITAS DE AHORA}

La cúpula dirigente empieza la búsqueda de un sucesor, lc que recae en el hijo menor de Ezequiel, taxista de oficio, que es elegido como nuevo líder del AEMINPO.

En el 2001 no se produce la participación política del FREPAP en cuanto a candidato presidencial, porque argüían que el nuevo líder no estaba apto para ser candidato presidencial. Sólo participaron con una lista parlamentaria, no logrando curul alguno.

\section{¿LA OPORTUNIDAD PERDIDA?}

Después de la muerte de Ezequiel, los israelitas no han acabado de asimilar su desaparición, aunque mantienen sus iglesias y comportamiento. Teniendo un crecimiento vegetativo del número de feligreses, se están dejando de lado algunas prạ́cticas religiosas: el ayuno y la vigilia. Ya no se sanciona que algunas jóvenes no usen velo ni túnica. Especialmente estas jóvenes están comenzando a acceder a la educación superior (institutos superiores tecnológicos y pedagógicos, centros ocupacionales, universidades...), a diferencia de los varones, que no acceden.

Sus ingresos familiares fluctúan entre 400 - 600 soles mensuales (en el caso de Tarma), y en el campo laboral siguen manteniendo sus empleos como vendedores de golosinas, chupetes, galletas, emolientes, lustrabotas, albañiles, agricultores, etc.

El comportamiento de la iglesia es discreto, no hay campañas agresivas de búsqueda de fieles; lo que sí mantienen es guardar los sábados y demás fiestas.

A manera de conclusión, podemos señalar que los israelitas, al no participar políticamente en estas elecciones regionales y municipales, están perdiendo presencia y las posibilidades que han tenido desde sus inicios políticos, sobre todo por el caudal electoral que tienen cautivo. 